\title{
Prevalence of Campylobacter jejuni and Campylobacter coli in raw milk and some dairy products
}

\author{
Mona A. El-Zamkan and Karima G. Abdel Hameed
}

Department of Food Hygiene and Control, Faculty of Veterinary Medicine, South Valley University, Qena 83523, Egypt. Corresponding author: Mona A. El-Zamkan, e-mail: M_zam@vet.svu.edu.eg, KGAH: karima_galal2004@yahoo.com

Received: 15-05-2016, Accepted: 10-09-2016, Published online: 26-10-2016

doi: 10.14202/vetworld.2016.1147-1151 How to cite this article: El-Zamkan MA, Abdel Hameed KG (2016) Prevalence of Campylobacter jejuni and Campylobacter coli in raw milk and some dairy products, Veterinary World, 9(10): 1147-1151.

\begin{abstract}
Aim: This study was accomplished to test raw milk and certain dairy products sold in local markets of Qena, Egypt, for the presence of Campylobacter coli and Campylobacter jejuni.

Materials and Methods: A total of 150 samples of raw milk, kareish cheese, and yoghurt (50 samples each) were subjected first to enrichment in Bolton broth at $42^{\circ} \mathrm{C}$ for 2 days under a microaerobic condition, subsequently campylobacter blood free selective agar plates were cultured and incubated in the same condition of the broth. Based on the morphological and biochemical themes of the growing colonies, it was further classified into Campylobacter spp. The identified isolates were later affirmed by polymerase chain reaction using primers that were designed to locate hip $\mathrm{O}$ genes in $C$. jejuni and gly $\mathrm{A}$ in C. coli.
\end{abstract}

Results: Of the total 150 examined samples of raw milk and soft cheese samples; 37 (24.6\%) samples were contaminated with Campylobacter spp. C. jejuni was dominating in this study in $20 \%, 14 \%$, and $8 \%$ of the examined raw milk, kareish cheese, and yoghurt samples, respectively. No sample harbored C. coli.

Conclusion: Campylobacter spp. could be detected in $24.6 \%$ of the investigated samples. C. jejuni isolated from $14 \%$ of the total tested samples, while $C$. coli could not be detected from the examined samples. Campylobacter spp. is rampant in the areas of poor hygienic conditions making products made from raw milk of public health hazard.

Keywords: Campylobacter coli, Campylobacter jejuni, dairy products, multiplex polymerase chain reaction, raw milk.

\section{Introduction}

Campylobacteriosis is a massed description for zoonotic diseases that caused by the bacterial genus Campylobacter which is accounted as a leading human food-borne pathogen and it is currently considered to be the main cause of bacterial gastroenteritis worldwide [1,2]. Campylobacter spp. initiated 7.5 million disability-adjusted life years in the study carried out by the Global Burden of Disease in 2010, it overtopped Shigella (7.1 million) and enterotoxigenic Escherichia coli (6.9 million) [3].

About 20 species are members of the Campylobacter genus, of these; Campylobacter jejuni and Campylobacter coli are responsible for most of the infections caused by this bacterium $[4,5]$. Campylobacter spp., mainly $C$. jejuni and C. coli induce enteric diseases that vary from a watery, nonbloody, non-inflammatory diarrhea to a severe inflammatory diarrhea with abdominal pain, fever, and malaise [5]. However, Guillain-Barré syndrome (GBS), which is a serious neurological disease with symptoms

Copyright: El-Zamkan and Abdel Hameed. Open Access. This article is distributed under the terms of the Creative Commons Attribution 4.0 International License (http://creativecommons. org/licenses/by/4.0/), which permits unrestricted use, distribution, and reproduction in any medium, provided you give appropriate credit to the original author(s) and the source, provide a link to the Creative Commons license, and indicate if changes were made. The Creative Commons Public Domain Dedication waiver (http:// creativecommons.org/publicdomain/zero/1.0/) applies to the data made available in this article, unless otherwise stated. that include flaccid paralysis, Reiter's syndrome or reactive arthritis may appear as serious postinfection sequelae [6-9]. The Campylobacter infection's epidemiology in developed countries is significantly different to that in the developing world. In developing countries, Campylobacter enteritis has no preference for seasonality; in contrast, campylobacteriosis epidemics occur in summer and autumn in developed countries $[1,10]$.

A number of transmission means have been blamed to the transmission of Campylobacter spp. to human, including consumption or handling of food as raw or underdone poultry or meat, raw milk and milk products [11]. Dairy products are predetermined as the main source of Campylobacter infection to human, as it ranked the first among food associated with Campylobacteriosis outbreaks $[12,13]$. This study aimed to explore the incidence of Campylobacter spp. in some dairy products with special concentration on C. jejuni and C. coli as a pathogen of major public health importance.

\section{Materials and Methods \\ Ethical approval}

Ethical approval is not required to pursue this type of study.

\section{Design of study}

This study was conducted within September 2014-February 2015 in the Department of Food 
Hygiene and Control, Faculty of Veterinary Medicine, South Valley University, Qena, Egypt.

\section{Samples collection}

A total of 150 samples of raw milk, kareish cheese, and yoghurt (50 samples each) were collected from local markets and street vendors in Qena city, Egypt. These samples were transferred to laboratory directly to be examined for the presence of $C$. jejuni and $C$. coli.

\section{Isolation of Campylobacter spp. from samples}

The preparation of the samples and isolation of Campylobacter spp. from the examined samples was done according to FDA [14]. The $\mathrm{pH}$ of the samples was adjusted to $7.5 \pm 0.2$, and then centrifugation of $50 \mathrm{~g}$ portion at $20,000 \times \mathrm{g}$ for $40 \mathrm{~min}$ was attained. Supernatant was discarded and pellets were dissolved in $10 \mathrm{ml}$ Bolton broth (supplemented with Bolton broth Selective Supplement and Laked Horse Blood, Oxoid) and then was transmitted to $90 \mathrm{ml}$ enrichment broth and incubated at $42^{\circ} \mathrm{C}$ for $48 \mathrm{~h}$ in an anaerobic jar containing a gas generating Kit (Oxoid). The Campylobacter blood free selective agar (mCCDA-Preston, Oxoid) which was supplemented with CCDA selective supplement (Oxoid), were then streaked with a loopful of each enrichment broth, and subsequently, incubated at $42^{\circ} \mathrm{C}$ for $48 \mathrm{~h}$ under microaerobic condition. From 2 to 3 presumptive Campylobacter colonies were purified on Columbia blood agar (containing 7\% defibrinated sheep blood) without supplement. About 100 Campylobacter isolates were submitted to Gram-stain, oxidase, catalase, inability to grow aerobically at $25^{\circ} \mathrm{C}$, hippurate hydrolysis and resistance to naladixic acid and cephalothin to exclude Campylobacter spp. except $C$. jejuni and C. coli.

\section{Identification of $C$. jejuni and $C$. coli using multiplex polymerase chain reaction ( $\mathrm{MPCR}$ )}

From the biochemically confirmed Campylobacter isolates, 9 strains were selected to be submitted to PCR. From the tested strains, there were 4 suspected strains (one strain was giving a light grayish color in hippurate hydrolysis test, and the other 3 strains were suspected to be sensitive to nalidixic acid).

\section{DNA extraction}

DNA extraction from isolates was operated using the QIAamp DNA Mini kit (Qiagen, Germany, $\mathrm{GmbH}$ ) with remodeling of the manufacturer's recommendations. In brief, $200 \mu 1$ of the sample suspension was incubated with $10 \mu \mathrm{l}$ of proteinase $\mathrm{K}$ and
$200 \mu 1$ of lysis buffer at $56^{\circ} \mathrm{C}$ for $10 \mathrm{~min}$. Following the incubation, $200 \mu 1$ of $100 \%$ ethanol was added to the lysate. The sample was thereafter washed and centrifuged according to the manufacturer's recommendations. Nucleic acid was eluted with $100 \mu 1$ of elution buffer afforded with the kit.

\section{Multiplex Polymerase Chain Reaction (mPCR)}

mPCR was used to confirm Campylobacter isolates according to Wang et al. [15]. Primers used were supplied from Metabion (Germany). The used primers were intended to identify hip $\mathrm{O}$ genes in $C$. jejuni and gly A in C. coli. The primer sequences used are presented in Table-1.

PCR amplification and analysis of the PCR products.

The PCR mixture reaction $(50 \mu \mathrm{l})$ consisted of $25 \mu \mathrm{l}$ of EmeraldAmp Max PCR Master Mix (Takara, Japan), $1 \mu 1$ of each primer of 20 pmol concentrations, $9 \mu \mathrm{l}$ of water, and $12 \mu \mathrm{l}$ of DNA template. Amplification of DNA was accomplished with 35 cycles of the following: Primary denaturation at $94^{\circ} \mathrm{C}$ for $10 \mathrm{~min}$, annealing at $55^{\circ} \mathrm{C}$ for $30 \mathrm{~s}$ and extension at $72^{\circ} \mathrm{C}$ for $30 \mathrm{~s}$ with a final extension time of $72^{\circ} \mathrm{C}$ for 7 min (Table-1) in an Applied Biosystem 2720 thermal cycler. The products of PCR were separated by electrophoresis on $1.5 \%$ agarose gel (Applichem, Germany, GmbH) in $1 \times$ TBE buffer at room temperature using gradients of $5 \mathrm{~V} / \mathrm{cm}$. For gel analysis, $30 \mu \mathrm{l}$ of the products were loaded in each gel slot. A 100 bp DNA Ladder (Qiagen, Germany, $\mathrm{GmbH}$ ) was used to determine the fragment sizes. The gel was photographed by a gel documentation system (Alpha Innotech, Biometra), and the data were analyzed through computer software.

\section{Results and Discussion}

Results illustrated in Table-2 revealed that Campylobacter spp. were detected in $24.6 \%$ of the examined samples. No C. coli could be recovered from the samples, while $C$. jejuni could be isolated from $20 \% 14 \%$, and $8 \%$ of raw milk, kareish cheese, and yoghurt samples, respectively. C. jejuni is now thought to be a major promoting agent of GBS and it is associated with several pathogenic profiles of GBS, axonal subtypes following the contagion may be more severe [16]. The infective dosage of $C$. jejuni is considered to be small, as human feeding studies submit that about 400-500 bacteria may produce illness in some persons, while in others, greater numbers are required [17].

Table-1: Sequences of the oligonucleotide primers.

\begin{tabular}{lllcc}
\hline Target agent & Target gene & Primers sequences (5'-3') & Amplified segment (bp) & Reference \\
\hline C. jejuni & hipo & ACTTCTTATTGCTTGCTGC & 126 & Wang et al., 2002 \\
C. coli & glyA & GTAACAACAAGTAAAGAAGC & 323 & \\
& & TCCAGCAATGTGTGCAATG & &
\end{tabular}

C. coli=Campylobacter coli, C. jejuni=Campylobacter jejuni 
The presence of Campylobacter spp. in raw milk may be contributed to contamination during milking process from the farm environment through feces [18], or after milking due to poor hygienic conditions during storage and handling of milk plus the major role played by workers in accelerating the incidence of the Campylobacter through cross contamination. Lower results recorded by Barakat et al. [19] who isolated C. jejuni from $4.4 \%$ of the investigated samples, while Yang et al. [17] obtained higher results as they could isolate $C$. jejuni from $26 \%$ of the examined raw milk samples. On the contrary, Muehlherr et al. [20] and Haghi et al. [21] could not isolate $C$. jejuni from milk samples and Gergs [22] isolated C. coli from 3\% of the samples. Kareish cheese is one of the soft cheeses that are made from raw cow's or buffaloes' milk in farmers' houses, so raw milk is a potential source of kareish cheeses contamination $[23,24]$. The usage of raw milk in the manufacturing of kareish cheese and the unhygienic conditions of preparation, processing, handling, storage, and selling methods explains the existence of highest positive samples among kareish cheese samples. The incidence of $C$. jejuni in this study is higher than Barakat et al. [19], who could isolate C. jejuni in 6.7\% of the samples, while El-Sharoud [25] could not detect Campylobacter spp. in the examined kareish cheese samples. Contrary to our results Mina and Thanaa [26] isolated C. coli from kareish cheese samples.

The lowest incidence of Campylobacter spp. was found in yoghurt and this may have resulted from the low $\mathrm{pH}$ which hinders survival and growth of Campylobacter spp. [25]. The obtained result is closely related to those obtained by Aygun and Pehlivanlar [27] who could isolate C. jejuni from $6 \%$ of the samples while Barakat et al. [19] detected C. jejuni in a higher percent of the examined samples (13.4\%). Like El-Sharoud [25], no C. coli could be determined in the inspected samples.

Substandard hygienic and sanitary condition and the tight closeness to animals in developing countries all backup the easy and recurrent attainment of any enteric pathogen including Campylobacter. Campylobacteriosis is deeply endemic in developing countries [10]. The major provenances of human infections are environmental pollution and foods. The results showed in this study display raw milk and dairy products as a mean of Campylobacter transmission.

Nowadays, in developing countries, as rule raw milk is boiled before being fed to babies, children, and other family members to protect them from fatal milkborne infections, but still, there is a potential threat from consumption artisanal products made from raw milk. Taylor et al. [13] notified that Campylobacter outbreaks are much associated with contaminated dairy products as they found that dairy products were implicated in 65 (29\%) out of 225 Campylobacter initiated foodborne outbreak in the US. Campylobacteriosis is a pediatric disease in developing countries as it has been stated that 60,000 per 100,000 children below 5 years of age are distressed by Campylobacter infections. In general, developing countries including Egypt do not have internal superintending recording system for Campylobacter foodborne outbreaks; therefore, incidence values expressed in the form of the number of patient cases for a population do not exist. Most evaluations of incidence in developing countries are collected from laboratory-based surveillance of pathogens responsible for diarrhea [28].

The isolate that gave the weak reaction of the hippurate hydrolysis was confirmed to be $C$. jejuni using multiple PCR (Figure-1). That weak reaction, caused by that $C$. jejuni strain, may be resulted from using low bacterial concentration in the test. Nakari et al. [29] found that $32 \%$ of the 145 strains that gave the negative reaction in the standardized hippurate test turned out to be $C$. jejuni by PCR and 9 of these strains were responsible for an outbreak. These

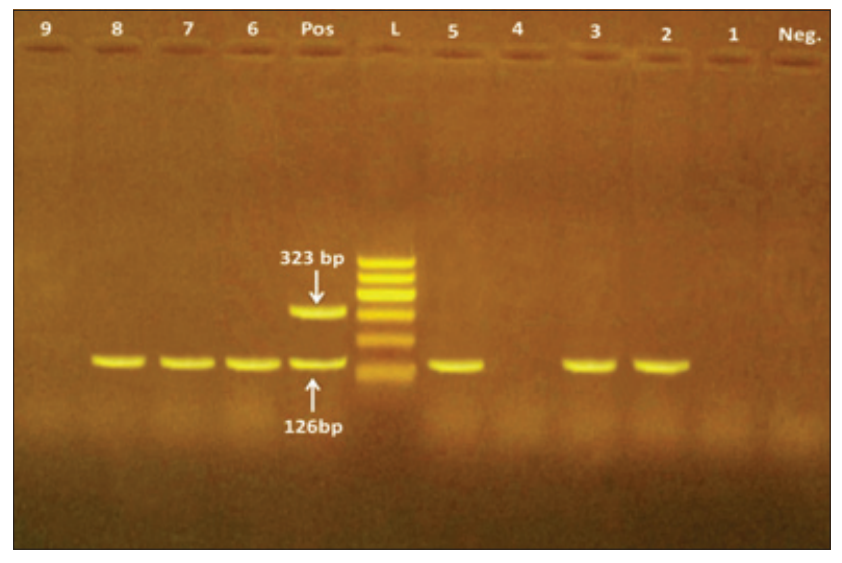

Figure-1: Multiplex-polymerase chain reaction of Campylobacter jejuni and Campylobacter coli strains isolates from raw milk, Kareish cheese and yoghurt samples. Lane (POS): Positive control. Lane (Neg): Negative control. Lane (L): 100 bp ladder as DNA marker. Lanes 2, 3, 5, 6, 7, 8 are positive for $C$. jejuni only. Lanes 1, 4, 9 are negative for both $C$. jejuni and $C$. coli. Lane 2: The strain gave a weak hippurate reaction.

Table-2: Incidence of Campylobacter spp. in the examined samples.

\begin{tabular}{|c|c|c|c|c|c|}
\hline \multirow[t]{2}{*}{ Samples } & \multirow[t]{2}{*}{ Number samples } & \multicolumn{4}{|c|}{ No. (\%) } \\
\hline & & Campylobacter spp. & C. jejuni & C. coli & Other Campylobacter spp. \\
\hline Raw milk & 50 & $11(22)$ & $10(20)$ & $0(0)$ & $1(2)$ \\
\hline Kareish cheese & 50 & $17(34)$ & $7(14)$ & $0(0)$ & $10(20)$ \\
\hline Yogurt & 50 & $9(18)$ & $4(8)$ & $0(0)$ & $5(10)$ \\
\hline Total & 150 & $37(24.6)$ & $21(14)$ & $0(0)$ & $16(10.6)$ \\
\hline
\end{tabular}

C. coli=Campylobacter coli, C. jejuni=Campylobacter jejuni 
situations proved that phenotypic tests should be reinforced by the molecular method for the authoritative recognition of $C$. jejuni and $C$. coli; hence making the epidemiological statistics on the infections caused by Campylobacter spp. is more authentic.

\section{Conclusion}

Campylobacter spp. occurred in $24.6 \%$ of the examined samples. About $56.7 \%$ of the isolated strains were identified as $C$. jejuni and no $C$. coli could be detected in the samples using culture and PCR methods. The high incidence of Campylobacter spp. in this study could be contributed to the unhygienic condition applied during production, and storage and also to the warm weather which help the microorganism to grow and multiply and also it shows the need for the increase awareness of the farmers and the small producers for the hygienic precautions during production.

\section{Authors' Contributions}

MAE conceived, designed the study, drafted and revised the manuscript. KGAH and MAE collected and analyzed samples. Both authors read and approved the final manuscript.

\section{Acknowledgments}

The authors are grateful to all staff members of the Food Hygiene and Control Department, Faculty of Veterinary Medicine, South Valley University, Qena, Egypt for their technical help.

\section{Competing Interests} interests.

The authors declare that they have no competing

\section{References}

1. Platts-Mills, J.A. and Kosek, M. (2014) Update on the burden of Campylobacter in developing countries. Curr. Opin. Infect. Dis., 27(5): 444-450.

2. Wei, B., Cha, S.Y., Yoon, R.H., Kang, M., Roh, J.H., Seo, H.S., Lee, J.A. and Jang, H.K. (2016) Prevalence and antimicrobial resistance of Campylobacter spp. isolated from retail chicken and duck meat in South Korea. Food Control, 62: 63-68.

3. Murray, C.J., Vos, T., Lozano, R., et al. (2012) Disabilityadjusted life years (DALYs) for 291 diseases and injuries in 21 regions, 1990-2010: A systematic analysis for the Global Burden of Disease Study 2010. Lancet, 380: 2197-2223.

4. Gharst, G., Oyarzabal, O.A. and Hussain, S.K. (2013) Review of current methodologies to isolate and identify Campylobacter spp. From foods. J. Microbiol. Methods, 95: 84-92.

5. Vencia, W., Nogarol, C., Bianchi, D.M., Gallina, S., Zuccon, F., Adriano, A., Gramaglia, M. and Decastelli, L. (2014) Validation according to ISO 16140:2003 of a commercial real-time PCR-based for detecting Campylobacter jejuni, C. coli, and C. lari in foods. Int. J. Food Microbiol., 177: 78-80.

6. Blaser, M.J. and Engberg, J. (2008) Clinical aspects of Campylobacter jejuni and Campylobacter coli infections. In: Nachamkin, I., Szymanski, C.M., Blaser, M.J., editors. Campylobacter. ASM Press, Washington, DC. p99-121.

7. Smith, J. (2002) Campylobacter jejuni infection during pregnancy: Long-term consequences of associated bacteremia, Guillain-Barre syndrome, and reactive arthritis.
J. Food Prot., 65(4): 696-708.

8. Connor, B.A. and Riddle, M.S. (2013) Review post-infectious sequelae of travelers' Diarrhea. J. Travel Med., 20: 303-312.

9. Ganan, M., Silvan, J.M., Carrascosa, A.V. and MartinezRodriguez, A.J. (2012) Review, alternative strategies to use antibiotics or chemical products for controlling Campylobacter in the food chain. Food Control, 24: 6-14.

10. Coker, K.O., Isokpehi, R.D., Bolaji, N., Thomas, B.N., Amisu, K.O. and Obit, C.L. (2002) Human campylobacteriosis in developing countries. Emerg. Infect. Dis., 8: 237-243.

11. Hussain, I., Mahmood, M.S., Akhtar, M. and Khan, A. (2007) Prevalence of Campylobacter species in meat, milk and other food commodities in Pakistan. J. Food Microbiol., 24: 219-222.

12. Painter, J.A., Hoekstra, R.M., Ayers, T., Tauxe, R.V., Braden, C.R., Angulo, F.J. and Griffin, P.A. (2013) Attribution of foodborne illnesses, hospitalizations, and deaths to food commodities by using outbreak data, United States, 1998-2008. Emerg. Infect. Dis., 19: 407-415.

13. Taylor, E.V., Herman, K.M., Ailes, E.C., Fitzgerald, C., Yoder, J.S., Mahon, B.E. and Tauxe, R.V. (2013) Common source outbreaks of Campylobacter infection in the USA. Epidemiol. Infect., 141: 987-996.

14. FDA. (2001) Campylobacter. Ch. 7. In: Bacteriological Analytical Manual. Available from: http://www.fda. gov/Food/FoodScienceResearch/LaboratoryMethods/ ucm072616.htm. Accessed on 21-08-2016.

15. Wang, G., Clark, C.G., Taylor, T.M., Pucknell, C., Barton, C., Price, L., Woodward, D.L. and Rodgers, F.G. (2002) Colony multiplex PCR assay for identification and differentiation of Campylobacter jejuni, C. coli, C. lari, C. upsaliensis, and C. fetus subsp. Fetus. J. Clin. Microbiol., 40: 4744-4747.

16. Nyati, K.K. and Nyati, R. (2013) Role of Campylobacter jejuni infection in the pathogenesis of Guillain-Barre syndrome: An update. Biomed. Res. Int., 2013: 852195.

17. Yang, C., Jiang, Y., Huang, K., Zhu, C. and Yin, Y. (2003) Application of real-time PCR for quantitative detection of Campylobacter jejuni in poultry, milk and environmental water. FEMS Immunol. Med. Microbiol., 38: 265-271.

18. Callon, C., Gilbert, F.B., Cremoux, R.D. and Montel, M.C. (2008) Application of variable numbers of tandem repeat analysis to determine the origin of $S$. aureus contamination from milk to cheese in goat cheese farms. Food Control, 19: $143-150$

19. Barakat, A.M.A., Mona, M.S., El Fadaly, H.A.A., Nagwa, S.R., Nashwa, O.K., Eman, R.H., Kotb, M.H.R., Zeinab, M.S., Girh, A., Dalia, M.S. and Mona, S.Z. (2015) Zoonotic hazards of campylobacteriosis in some areas in Egypt. Life Sci. J., 12(7): 9-14.

20. Muehlherr, J.E., Zweifel, C., Corti, S., Blanco, J.E. and Stephan, R. (2011) Microbiological quality of raw bulktank milk in Switzerland. J. Dairy Sci., 86(12): 3849-3856.

21. Haghi, F., Zeighami, H., Naderi, G., Samei, A., Roudashti, S., Bahari, S. and Shirmast, P. (2015) Detection of major foodborne pathogens in raw milk samples from dairy bovine and ovine herds in Iran. Small Rumin. Res., 131: 136-140.

22. Gergs,A.E. (2004) The Zoonotic Importance of Campylobacter Infection in Man and Animals. Thesis, (M. Sc). Faculty of Veterinary Medicine, Assiut University, Egypt.

23. Robison, R.K. (1990) Dairy Microbiology. $2^{\text {nd }}$ ed. Chapman and Hall, London, New York.

24. André, M.C.D., Campos, M.R.H., Borges, L.J., Kipnis, A., Pimenta, F.C. and Serafini, A.I.B. (2008) Comparison of Staphylococcus aureus isolates from food handlers, raw bovine milk and minas frescal cheese by antibiogram and pulsed field gel electrophoresis following SmaI digestion. Food Control, 19: 200-207.

25. El-Sharoud, W.M. (2009) Prevalence and survival of Campylobacter in Egyptian dairy products. Food Res. Int. J., 42(55-6): 622-626. 
26. Mina, H. and Thanaa, N. (2004) Occurrence of Campylobacter species in milk and some milk products. Thesis, (M.V.Sc). Faculty of Veterinary Medicine, Assiut University, Egypt.

27. Aygun, O. and Pehlivanlar, S. (2006) Campylobacter and Listeria species in the raw milk and dairy products in Antakya, Tyrkey. Food Control, 17(8): 676-679.

28. Epps, S.V.R., Harvey, R.B., Hume, M.E., Phillips, T.D.,
Anderson, R.C. and Nisbet, D.J. (2013) Foodborne Campylobacter: Infections, metabolism, pathogenesis and reservoirs. Int. J. Environ. Res. Public Health, 10: 6292-6304.

29. Nakari, U.M.A., Puhakka, A. and Siitonen, A. (2008) Correct identification and discrimination between Campylobacter jejuni and C. coli by a standardized hippurate test and species-specific polymerase chain reaction. Eur. J. Clin. Microbiol. Infect. Dis., 27: 513-518.

$* * * * * * * *$ 